\title{
MAPA DE FLUXO DE VALOR - ESTUDO DE CASO EM UMA INDÚSTRIA METALÚRGICA
}

\section{VALUE STREAM MAPPING - CASE STUDY IN A METALLURGICAL INDUSTRY}

\author{
Rogério Royer ${ }^{1}$, Ariane Ferreira ${ }^{2}$, Lucas Nienow dos Santos ${ }^{3}$ \\ ${ }^{1}$ Universidade Federal de Pelotas - UFPel - Pelotas - Brasil \\ rogroyer@ufrgs.br \\ ${ }^{2}$ Universidade Federal de Pelotas - UFPel - Pelotas - Brasil \\ afprosa61@gmail.com \\ ${ }^{3}$ Universidade Federal de Pelotas - UFPel - Pelotas - Brasil \\ lgns.santos@gmail.com
}

\begin{abstract}
Resumo
A produção enxuta propõe a simplificação do processo produtivo através da eliminação das perdas. Para tanto, torna-se necessária a visualização processo produtivo, a compreensão de suas etapas e do fluxo de materiais a fim de identificar as perdas. O Mapa de Fluxo de Valor (MFV) tem se mostrado uma ferramenta importante do sistema de produção enxuta usada para a identificação e eliminação de desperdícios. No MFV a fabricação do produto é representada por seus processos produtivos dispostos em sequência para a obtenção da visibilidade do processo produtivo a fim de simplificá-lo. Este artigo apresenta uma revisão teórica, onde são descritos alguns conceitos e definições da produção enxuta, do MFV, bem como as ferramentas utilizadas. $O$ artigo apresenta um estudo de caso realizado em uma indústria metalúrgica. No estudo de caso o fluxo do material e das informações foi mapeado, de forma a identificar os desperdícios, bem como a fonte dos mesmos no fluxo de valor. Após a identificação dos gargalos, elaborou-se o mapa do "estado futuro" mostrando-se como o valor deve fluir, e criando-se um plano de ação para tornar efetivas as propostas de melhorias.
\end{abstract}

Palavras-chave: mapeamento de fluxo de valor; produção enxuta, indústria metalúrgica.

\section{Introdução}

Nos últimos tempos, diante dos novos cenários de competitivos, no Brasil e no mundo, o setor produtivo brasileiro vem sofrendo uma série de mudanças estruturais. Seus produtos competem em preço e qualidade com similares estrangeiros, vindo tanto de países com elevado desenvolvimento tecnológico, como os EUA, quanto de países onde os custos de fabricação estão num patamar bem mais baixo, como a China e a Índia. Isso força a indústria brasileira a assimilar e 
desenvolver continuamente novas tecnologias e produtos visando a maximização da produção juntamente com a redução de custos, e se possível a ampliação de mercado (SALGADO et al.,2009).

Sob este ponto de vista percebe-se a necessidade de se aumentar a produtividade da indústria nacional para que a mesma possa ser competitiva e sobreviver no atual cenário. Segundo NAZARENO (2003), um dos aspectos que tem contribuído para o aumento da produtividade das organizações no Brasil são os avanços que relacionados ao desenvolvimento e a implementação de técnicas do Sistema de Produção Enxuta (Lean Manufacturing).

O Mapeamento do Fluxo de Valor é uma das ferramentas da Produção Enxuta, a qual objetiva enxergar os desperdícios contidos no sistema de produção e propor melhorias. Ferro (2015) conceitua o Mapeamento do Fluxo de Valor como "uma ferramenta capaz de olhar para os processos de agregação de valor horizontalmente". Ou seja, permite que se obtenha uma visão completa do fluxo do valor da produção agregando-se o fluxo de materiais e o fluxo de informações no mesmo mapa.

Considerando este contexto, observa-se que a realização de um estudo de Mapeamento do Fluxo de Valor em uma empresa pode gerar informações úteis para melhorar a produtividade. Neste sentido, este artigo apresenta como tema a aplicação do mapeamento do fluxo de valor em uma empresa de revestimentos de peças industriais por aspersão térmica.

Empresas do setor industrial, como a que será apresentada neste estudo, necessitam atender a uma série de requisitos técnicos na sua produção. Para garantir tais requisitos é necessário que se analise os processos que compõe todo o sistema produtivo, porém, quase que sempre, esta análise é feita de forma discreta, processo por processo. Todavia analisar processos de maneira discreta pode dificultar a identificação de problemas que afetam o bom o rendimento da produção. Muitas vezes empresas buscam melhorias isoladas em seus processos, sem considerarem o fluxo da produção em todo o seu sistema produtivo, resultando assim em melhorias pontuais que podem não contribuir para todo o sistema.

Segundo Ferro (2015), o Mapeamento do Fluxo de Valor (MFV) permite que empresas enxerguem seus desperdícios, servindo para direcionar os esforços da empresa para as melhorias no fluxo de valor que efetivamente contribuam para um salto no seu desempenho, evitando-se assim a dispersão de recursos em melhorias pontuais que contribuem apenas com um pequeno resultado final e que possuam pouca sustentação ao longo do tempo.

Tendo em vista este cenário, o presente trabalho tem por objetivo principal investigar o fluxo de valor de uma empresa que aplica revestimentos contra desgastes em peças industriais, através dos conceitos desenvolvidos da produção enxuta de acordo com os conceitos propostos por 
Rother e Shook (2012), identificando-se perdas e propondo melhorias. Para alcançar este objetivo serão também:

- Investigados os processos fabris da empresa estudada para então identificar a família de produtos a ser analisada;

- Compreendidos o fluxo de materiais e de informações existentes;

- Identificados os desperdícios e elaborada uma proposta para o estado futuro desejado;

- Elaborado um plano de ação para implantar as melhorias propostas.

Este artigo encontra-se estruturado em seis seções. A primeira seção mostra esta introdução como forma de esclarecer o que será realizado. A segunda seção apresenta a revisão teórica necessária para a execução do estudo, e a seção 3 apresenta os procedimentos metodológicos utilizados para alcançar o objetivo descrito. Na seção 4 descreve-se o estudo de caso realizado, o qual aplicou os procedimentos metodológicos descritos e na seção 5 apresentam-se as conclusões deste trabalho. Por fim, serão apresentadas as bibliografias referenciadas.

\section{Revisão Bibliográfica}

Esta seção apresenta os conceitos de Produção Enxuta, Mapeamento do Fluxo de Valor (MFV) e a ferramenta $5 \mathrm{~W} 2 \mathrm{H}$, de forma a apresentar os aspectos teóricos necessários a execução do trabalho proposto.

\subsection{Produção Enxuta}

A partir do fim da Segunda Guerra Mundial começou a surgir no Japão uma nova filosofia de produção. Eram tempos de crise econômica no país e notava-se a necessidade de eliminar desperdícios e aumentar a eficiência produtiva.

Dentro deste contexto, a empresa Toyota começou a desenvolver um sistema de produção tido até hoje como referência em produtividade, qualidade e flexibilização, o Sistema Toyota de Produção (STP) que se tornou referência mundial na indústria automobilística. Nos anos 80 as empresas ocidentais começaram a perder espaço para as empresas japonesas e sentiram a necessidade de se adaptar à filosofia adotada pela Toyota, surgindo assim o conceito de Produção Enxuta ou Lean Manufacturing (LM).

A mentalidade enxuta (Lean Thinking) visa produzir cada vez mais com cada vez menos. Para que isso seja possível, é necessária a utilização de seus princípios: especificar o valor, identificar a cadeia de valor, o fluxo de produção puxada e a perfeição (WOMACK e JONES, 2004). 
Muitos dos esforços de implementação da produção enxuta buscam a eliminação dos "sete desperdícios (ou perdas)" enunciados por Shingo: superprodução, transporte, processamento, fabricação de produtos defeituosos, movimento, espera e estoque (SHINGO, 1996).

O conceito Lean Thinking parte do pressuposto que cinco princípios devam ser considerados, são eles: valor, fluxo de valor, fluxo contínuo, produção puxada e perfeição. Entendese por valor, a definição do mesmo sob a ótica do cliente, o que é percebido pelo consumidor final. Por consequência, entender o fluxo do valor nos permite identificar e redefinir processos, de forma a reduzir, ou até, eliminar o que não é percebido como agregação de valor.

\subsubsection{As Sete perdas}

Shingo (1996) classifica as perdas em 7 tipos: superprodução, transporte, processamento, fabricação de produtos defeituosos, movimento, espera e estoque. As sete perdas são listadas abaixo:

- Perdas por superprodução: referem-se à produção de itens acima do necessário ou antecipadamente;

- Perdas por transporte: referem-se basicamente às atividades de movimentação de materiais, as quais usualmente não adicionam valor ao produto;

- Perdas no processamento: propriamente dito correspondem às atividades de transformação desnecessárias para que o produto adquira suas características básicas de qualidade;

- Perdas por fabricação de produtos defeituosos: como o nome indica, originam-se na confecção de itens fora das especificações de qualidade;

- Perdas no movimento: relacionam-se à movimentação inútil na consecução das atividades, ou seja, à ineficiência da operação propriamente dita;

- Perdas por espera: são formadas pela capacidade ociosa, quer dizer, por trabalhadores e instalações parados, o que gera custos;

- Existência de estoques: gera as perdas por estoque, as quais são os custos financeiros para a manutenção dos estoques, custos devidos à obsolescência dos itens estocados e, principalmente, custos de oportunidade pela perda de mercado futuro para a concorrência com menor "lead time".

\subsubsection{Fluxo Contínuo ou Enxuto}

O principal objetivo do MFV é a criação de um fluxo de valor contínuo (ou enxuto). Para a criação desse fluxo contínuo, muitas fábricas concentraram seus esforços na criação de layouts em forma de "U", ao invés de criar e manter um fluxo contínuo eficiente, que é o mais importante. Para 
atingir e manter um eficiente fluxo contínuo, as peças devem ser transferidas de uma etapa para outra sincronizadamente. Para facilitar e auxiliar nesse objetivo, o processo é dividido em células (ROTHER e HARRIS, 2002). Algumas vantagens do fluxo contínuo são:

- Uso do mínimo de recursos como quantidade de pessoas, máquinas, materiais, prédios, equipamentos de movimentação, entre outros recursos, mantendo um mínimo necessário para a produção, o que implica em alta produtividade e baixo custo;

- Lead time curto visa minimizar o tempo de resposta ao cliente, além disso, diminuir o tempo de conversão de dinheiro, ou seja, o tempo entre pagar a matéria-prima e receber o pagamento dos produtos reduz.

O fluxo contínuo nos estabelece uma relação de força ente os processos que restam e garantem uma maior confiabilidade dos mesmos. Desta forma, podemos produzir de forma puxada, fazendo apenas o que for solicitado.

Com a percepção e com as ações impostas pelos princípios interiores, conseguimos atingir a perfeição, ou Kaizen, através de uma melhoria contínua de tudo que está envolvido no fluxo de valor. Além disso, Lean Thinking também pode ser entendido como um sistema de gestão e também uma estratégia de negócios voltada exclusivamente para aumentar a satisfação dos clientes.

O LM, além do esforço para eliminação dos desperdícios, caracteriza-se também pela não aceitação da situação vigente ou ainda de padrões arbitrários de desempenho. Na abordagem tradicional as metas costumam ser estáticas, para determinado período de tempo, depois podem ser alteradas para aprimoramentos. Essas metas funcionam como padrões, com base nos quais é exercida a atividade de controle que procura minimizar os afastamentos que ocorrem em relação a estes padrões. O controle mantém o processo estável e os resultados dentro das tolerâncias aceitáveis (CORRÊA et al., 1996).

O LM possui as seguintes metas para solução dos vários problemas de produção: zero defeitos; tempo zero de preparação ( et up); estoque zero; movimentação zero; quebra zero; lead time zero; e lote unitário.

O modelo LM possui várias metodologias e técnicas de produção e gestão industrial que são utilizadas atualmente pelas empresas. Algumas dessas surgiram no decorrer das últimas décadas, como por exemplo: Just-In-Time (JIT); Total Quality Management (TQM); Total Productive Maintenance (TPM); e Filosofia Kaizen. Para Rother e Shook (2012), o MFV surgiu para preencher os objetivos supracitados, enfocando todo o fluxo de produção de um produto ou família de produtos, visando à implantação da produção enxuta em todo o fluxo. 


\subsection{Mapeamento do Fluxo de valor}

O Mapeamento do Fluxo de Valor (MFV) é uma técnica de modelagem proposta por Rother e Shook (2012). Seus princípios baseiam-se na identificação e eliminação de desperdícios encontrados ao longo do processo produtivo, como por exemplo, estoques e tempos de espera elevados (NAZARENO, 2003).

De acordo com Rother e Shook (2012), fluxo de valor é toda ação (agregando valor ou não) necessária para transformação da matéria prima em um produto final até sua entrega ao cliente. O MFV é uma ferramenta que busca facilitar a visualização do processo de produção e a identificar eventuais desperdícios, mostrando a relação entre o fluxo de materiais e de informação.

As etapas do MFV são resumidas de acordo com o esquema mostrado na Figura 1.

Figura 1- Etapas do mapeamento do fluxo de valor

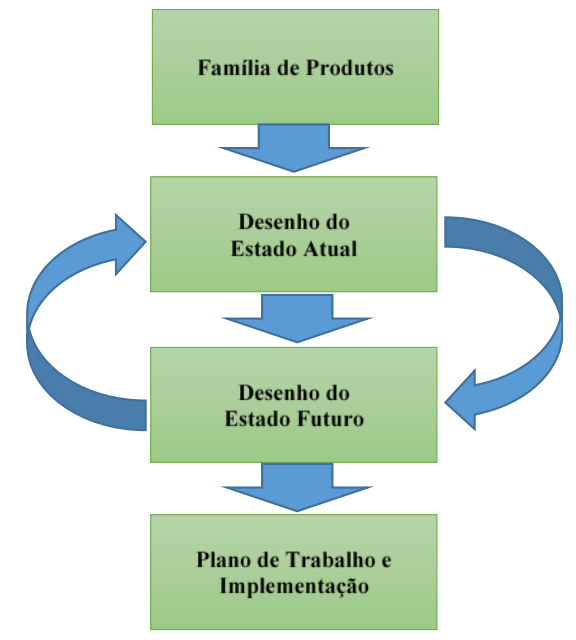

Fonte: adaptado de Rother e Shook (2012)

O Mapeamento do Fluxo de Valor (MFV) é uma técnica de modelagem proposta por Rother e Shook (2012). Seus princípios baseiam-se na identificação e eliminação de desperdícios encontrados ao longo do processo produtivo, como por exemplo, estoques e tempos de espera elevados (NAZARENO, 2003).

As etapas apresentadas na Figura 1 são detalhadas a seguir:

Seleção de uma família de produtos: Rother e Shook (2012) definiram a família de produtos como um grupo de produtos que passam por etapas semelhantes de processamento e utilizam equipamentos comuns nos seus processos anteriores. A escolha da família de produtos para o mapeamento de seu processo deve partir do lado do consumidor.

Desenho do estado atual: Inicialmente mapeia-se o fluxo como está ocorrendo atualmente, a partir de dados coletados no chão de fábrica.

Nesta etapa são observados e mapeados os fluxos de informação e o fluxo de material da família de produtos que foi selecionada, assim como os seguintes dados para cada um dos processos que fazem parte do sistema produtivo: 
- Tempo de ciclo, ou seja, o tempo necessário para que um componente complete um processo em segundos;

- Tempo de troca, o tempo necessário para mudar a produção de um produto para outro;

- Disponibilidade, o tempo disponível por turno de trabalho, descontando-se os tempos de parada e manutenção;

- Tamanho dos lotes de produção (TPT);

- Número de operadores;

- Tempo de trabalho (descontando-se os intervalos);

- Taxa de refugo;

Após realizada a coleta dos dados, será feita a representação visual do Mapa do Fluxo de Valor no estado atual.

Na Figura 1 nota-se a existência de setas ligando os estados futuro e o atual, mostrando a dependência que há entre eles. Ou seja, durante a confecção do estado atual irão aparecer ideias para a criação do estado futuro, e no desenvolver deste, serão identificadas informações sobre o estado atual que antes não foram visualizadas.

Desenho do estado futuro: A partir dos problemas identificados na representação visual do Mapa do Fluxo de Valor do estado atual, realiza-se a representação do Mapa do Fluxo de Valor do estado futuro. O Mapa do Fluxo de Valor do estado futuro deve propor soluções para os problemas identificados no Mapa do Fluxo de Valor do estado atual.

Implementação de melhorias: O plano de implementação de melhorias descreverá como se planeja chegar ao estado futuro. Após tê-lo colocado em prática, um outro mapa do estado futuro deve ser desenhado, ou seja, deve ocorrer uma melhoria contínua no nível do fluxo de valor.

\subsubsection{Elementos integrantes do método}

O MFV é formado por vários elementos, ele tem como característica ser uma ferramenta padronizada. Essa padronização de termos e figuras tem como vantagem sua fácil leitura por quem quer conheça a ferramenta. Ao mesmo tempo, a ferramenta tem flexibilidade para adaptar elementos do mapa para se adequar a processos específicos.

O mapa de fluxo de valor é uma representação simbólica e concisa do fluxo de material e informação. Assim ele lança mão de alguns elementos representativos, sendo que os mais comuns são:

- Caixa de processo (representa as estações de processos): é o estágio onde se agrega valor ao produto. É entendido agregador de valor o local onde há modificação ou transformação de matéria ou informação; 
- Caixa de dados: é o elemento onde se descreve os dados relativos aos processos, os quais incluem o tempo de ciclo, o tempo de setup e outros que serão vistos a seguir. Cada caixa de processo possui uma caixa de dados;

- Identificação da forma com que o sistema flui: representando o sentido do fluxo de material e indicando se o fluxo é "empurrado" ou "puxado";

- Estoques: esse elemento indica a existência de estoque, seja em processo, matéria-prima ou produto final. Esse elemento é um dos mais importantes pois a existência de estoques revela a existência de problemas;

- Planta ou fábrica: representa um fornecedor ou cliente localizado fisicamente fora da empresa mapeada;

- Meio de transporte: utilizado para entrega e recebimento de produto acabado e matériaprima respectivamente;

- Fluxo de informação: esse elemento mostra o sentido em que flui a informação e se ela é eletrônica ou convencional.

A Figura 2 mostra alguns dos ícones usados para a técnica do MFV.

Figura 2 - Ícones utilizados no MFV
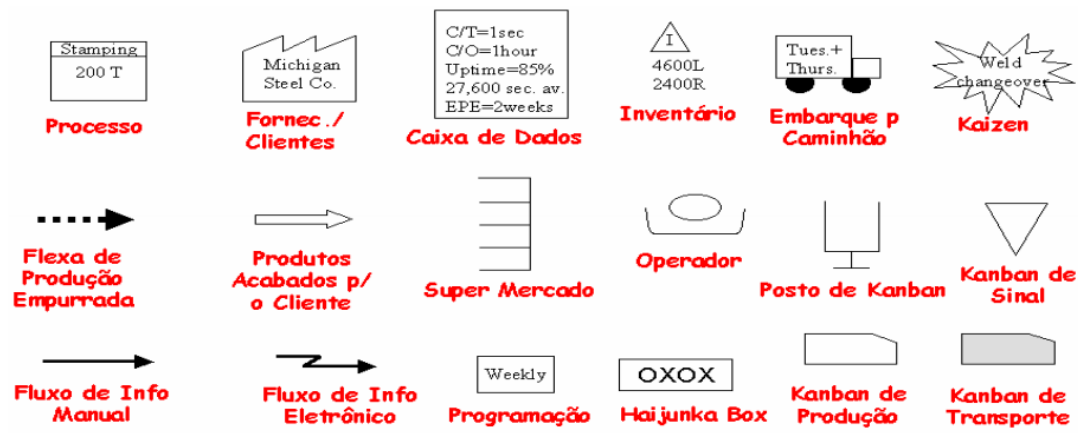

- Cliente

Super Mercado
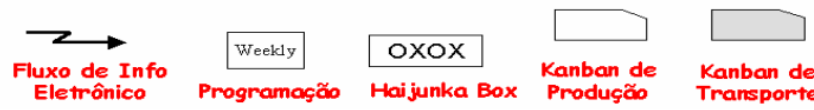

Fonte: Rother e Shook (2012)

\subsubsection{Elementos integrantes das caixas de dados}

A caixa de dados contém dados relativos a um determinado processo. O levantamento desses dados é de uma importância fundamental pois eles vão dar base à decisão de criar planos de melhoria. Eles são as informações base para melhorar o fluxo de valor.

O tempo de ciclo (T/C) é um dos dados mais comuns, o qual corresponde ao tempo para se fabricar um produto dentro de uma estação de processo. O T/C é o equivalente à capacidade de produção horária. Enquanto um mede 360 peças por hora, o T/C mede mesma informação como sendo 10 segundos o tempo para a produção de uma peça. A primeira vantagem em trabalhar com esse índice é poder balancear toda sua produção pelo tempo takt o qual também informa a demanda 
em segundos de cada peça. A outra vantagem é a separação do componente confiabilidade e T/C que estão misturados no índice de capacidade de produção horária.

Também é bastante comum ter-se a disponibilidade de máquina, sendo esta uma medida de confiabilidade. Ela está ligada ao tempo que a máquina está disponível para produção, costuma ser medido em porcentagem.

Além disso, o tempo de troca (TR) ou setup é um dado muito pertinente. O TR consiste basicamente no tempo entre a última peça de uma produção até o início da produção da primeira peça dentro das especificações do novo produto. O TR é um dado importante pois muitas vezes ele é a razão da produção em grandes lotes e a existência de grandes estoques em processo e produto acabado. A redução do TR está ligada à redução dos lotes de produção e consequentemente a redução dos estoques.

O TPT (Toda Parte Toda) é outro dado levantado. O TPT está ligado ao tamanho do lote. Se a empresa produz seus produtos com frequência de uma semana então o TPT é de uma semana. Em última análise reduzir o TPT é reduzir o lote.

Os outros dados levantados mais comuns na indústria, são: número de operadores na estação de trabalho, número de modelos do produto, taxa de refugo, tamanho da embalagem do processo ou lote de transferência.

\subsubsection{Linha indicadora de tempo}

Para a Toyota a eficiência do fluxo de valor é medida pelo lead time, isto é, quanto menor o lead time menor o volume de estoques no fluxo de valor e mais eficiente é a empresa. A linha indicadora de tempo do mapa de fluxo de valor é a forma de registrar, expor e calcular o lead time no mapa de fluxo de valor e o somatório dos tempos de ciclo de cada processo.

A linha de tempo é uma barra indicadora que fica na parte inferior do mapa de fluxo de valor. Ela basicamente compara o somatório dos tempos de ciclo de cada processo ao lead time, somatório do estoque em dias.

A mudança dos processos buscando a eliminação dos sete desperdícios e a implementação dos cinco princípios do lean necessariamente faz com que o lead time do processo diminua.

\subsubsection{Definir a família a ser mapeada}

Segundo Womack e Jones (2004), é vital investir um tempo considerável na definição de famílias, pois os mapas e as decisões serão tomadas para melhorar o fluxo para uma determinada família de produtos. Caso as famílias não estejam bem definidas os benefícios podem ser reduzidos. 
Uma das primeiras etapas para a construção de um mapa de fluxo de valor (MFV) é a escolha de uma família de produtos. Segundo Rother e Shook (2012), a menos que você tenha uma pequena empresa, uma planta de um único produto, desenhar todo o fluxo do produto com um único mapa é muito complicado. Vale ressaltar, que este mapeamento significa "andar pela fábrica e desenhar as etapas de processamento".

O processo de identificação de uma família de produtos se torna demasiado simples, uma vez que, entenda-se o conceito por trás do mesmo. Podemos classificar como uma família, um grupo de produtos que passe por células de produção semelhante, tendo o maior número de processos e equipamentos semelhantes possíveis em seu processamento.

Aconselha-se que se o mix de produtos é complicado, utilize-se da criação de uma matriz com todas as etapas de montagem e os equipamentos em um eixo e seus produtos no outro eixo (ROTHER e SHOOK, 2012).

A justificativa para escolha desta família pode ser feita de forma variada, no entanto, o mais importante é entender a interação dos clientes com a mesma, a demanda, a frequência de entregas, etc. Desta forma, as melhorias do processo irão impactar melhor os resultados, gerando um ganho substancial a empresa.

\subsubsection{Mapa do estado atual, mapa futuro e plano de ação}

O mapa do estado atual ou estado presente é um retrato instantâneo do fluxo de valor na manufatura. É uma fotografia onde se deve apenas registrar a realidade do momento. O mapa contém o fluxo de material e informação da empresa. No fluxo de material estão as estações de processo, seus dados, os estoques de matéria-prima, produto acabado e em processo, a forma que com que ocorre o suprimento pelos fornecedores e a expedição de produtos para os clientes.

Primeiramente, coletam-se dados no chão de fábrica e constrói-se um mapa com o fluxo atual. Estes dados arrecadados se fazem necessários também para o desenvolvimento do estado futuro. Um mapa para o estado futuro é elaborado com propostas de melhorias, que visam diminuir desperdícios e aumentar a agregação percentual de valor dos produtos.

As seguintes atividades permitem a construção do MFV atual do processo:

- Identificar as estações de processos no fluxo de valor: Entende-se por posto de trabalho, uma máquina, uma bancada a qual o material passe e por estação de trabalho o conjunto de postos de trabalho onde o material esteja fluindo. As estações de trabalho, como já foi dito, são representadas por uma caixa de processo. A regra geral para definir uma estação de trabalho é observar se entre os postos de trabalhos o material é transportado em lotes e se a amplitude da variação do estoque entre os postos de trabalho é grande. É importante 
observar isso pois vários postos de trabalho de uma célula de manufatura formam uma estação de trabalho (ROTHER e SHOOK, 2012).

- Identificar os desperdícios: Shingo (1996) afirma que as perdas não devem ser evitadas e sim eliminadas através de método científico para atacar a causa raiz do desperdício. $\mathrm{O}$ conceito apesar de ser simples, normalmente não é exercitado. Soluções para movimentações de materiais costumam ser automatizar a atividade. Reduzir o desperdício resume-se a fazer a atividade que não agrega valor mais rápido para não perder muito tempo. Shingo (1996) enfatiza a importância de pensar sem restrições e atacar a causa raiz do problema.

- Identificar estoques entre processo e calcular seus volumes em dias: Para o Lean, os estoques medem a ineficiência de um processo. Acredita-se que ele está ligado a alguma dificuldade ou ineficiência. A identificação dos estoques é feita com uma figura triangular com um "E" de estoque ou um "I" de inventário. No mapeamento eles são desenhados com um ícone na forma de triângulo de advertência para mostrar a localização e a quantidade de estoque. Conforme já foi mostrado, os estoques são calculados em dias para o cálculo do lead time.

- Levantamento dos dados de processo (caixa de dados): O levantamento dos dados das caixas de processo, já mencionado neste mesmo capítulo, é parte importante do método, pois eles ajudarão a tomar decisões nos planos de melhoria. Esse levantamento é um processo simples onde são medidos os tempos de ciclo (T/C) e os tempos de troca (TR).

- Identificar o fluxo de informação: A importância da informação para as organizações é universalmente aceita, constituindo, senão o mais importante, pelo menos um dos recursos cuja gestão e aproveitamento estão diretamente relacionados com o sucesso desejado. A informação também é considerada e utilizada em muitas organizações como um fator estruturante e um instrumento de gestão.

Retomando a visualização da Figura 1, observamos que os estados atual e futuro são interligados por duas setas, elas mostram a dependência dos mesmos. Isso se deve ao fato de que durante a construção do estadeado atual, surgem oportunidades de melhorias a serem desenhadas no estado futuro. Assim como durante o desenho do estado futuro pode-se vir a perceber alguma relação entre etapas de processo na planta atual antes não percebida.

Após a realização dos mapas de fluxo, é necessário a criação de um plano de implementação das melhorias propostas. Ele descreve como se planeja chegar ao estado futuro. Após tê-lo colocado 
em prática, outro mapa do estado futuro deve ser desenhado, ou seja, deve ocorrer uma melhoria contínua no nível do fluxo de valor.

\subsection{Ferramenta 5W2H}

A ferramenta 5W2H também surgiu no contexto do LM como auxilio na tomada de decisões de um plano de ação. Polacinski (2012) descreve a ferramenta como um plano de ação para atividades pré-estabelecidas que precisem ser desenvolvidas com a maior clareza possível.

No presente estudo optou-se por utilizar a ferramenta como suporte para a definição do estado futuro do fluxo de valor, consequentemente do plano de implementação de melhorias no processo estudado.

A Tabela 1 demonstra como deve ser elaborado o plano de ação através dos sete questionamentos do método $5 \mathrm{~W} 2 \mathrm{H}$.

Tabela 1 - Etapas para realização do método $5 \mathrm{~W} 2 \mathrm{H}$

\begin{tabular}{|c|c|c|c|}
\hline \multicolumn{4}{|c|}{ Método 5w2h } \\
\hline \multirow{5}{*}{$5 w$} & what? & O que? & Que ação será executada? \\
\hline & who? & Quem? & Quem irá executar/participar da ação? \\
\hline & where? & Onde? & Onde será executada a ação? \\
\hline & when? & Quando? & Quando será executada a ação? \\
\hline & why? & Por quê? & Por que será executada a ação? \\
\hline \multirow{2}{*}{$2 \mathrm{~h}$} & how? & Como? & Como será executada a ação? \\
\hline & how much? & Quanto custa? & Quanto custa para executar a ação? \\
\hline
\end{tabular}

Respondendo aos sete questionamentos apresentados na Tabela 1, pode-se estruturar um plano de ação. As respostas para os questionamentos, no caso deste trabalho, serão baseadas no mapeamento do estado futuro do fluxo de valor da empresa estudada e servirá para estabelecer um plano de ação com o intuito de atingir o mapa do estado futuro.

\section{Metodologia}

A pesquisa realizada neste artigo é exploratória, fundamentada em um estudo de caso de uma empresa metalúrgica localizada no Rio Grande do Sul. A metodologia usada foi de natureza aplicada, com objetivo exploratório, abordagem quali-quantitativa e o método foi a realização de um estudo de caso.

A metodologia utilizada no estudo de caso está estruturada em quatro etapas, sendo estas fundamentadas nos conceitos desenvolvidos por Rother e Shook (2012), conforme já mostrado na Figura 1.

Etapa 1: Seleção de uma família de produtos.

Etapa 2: Desenho do estado atual.

Etapa 3: Desenho do estado futuro.

Etapa 4: Implementação de melhorias. 
Para implantação do Mapa do Fluxo de Valor do estado futuro será elaborado um plano de ação estruturado através da ferramenta 5W2H, conforme foi mostrado na Tabela 1.

\section{Estudo de Caso}

A empresa alvo do estudo de caso está localizada na cidade de São Leopoldo, região metropolitana de Porto Alegre no Rio Grande do Sul. Esta empresa foi fundada em maio de 2002 por três sócios, com o intuito de fornecer soluções contra o desgaste superficial de peças mecânicas para a indústria. A empresa possui uma área construída de $2000 \mathrm{~m}$ agregando escritório, área fabril e área de lazer. Colaboram com a empresa cerca de 50 funcionários. A empresa tem como clientes outras empresas que desejam aplicar em suas peças e/ou produtos revestimentos metálicos e cerâmicos.

No período em que este estudo de caso foi realizado havia uma baixa demanda pelos trabalhos da empresa, o que era natural para a época escolhida, conforme relatou o gerente de produção. Portanto, o estudo de caso limitou-se a trabalhar com um único produto para o estudo de mapeamento do fluxo de valor.

Esta seção apresenta o estudo de caso aplicado no sistema produtivo da referida empresa através do desenvolvimento do conjunto de quatro etapas definidos pela metodologia.

\subsection{Seleção da família de produtos}

O produto escolhido para a realização do estudo de caso foram as "luvas de bombas hidráulicas", as quais são peças que possuem a função de evitar vazamentos em bombas. O cliente da empresa alvo é a fabricante destas peças, sendo que este terceiriza a aplicação do revestimento em cromo nas peças, objetivando o aumentando da sua vida útil. A Figura 3 mostra as luvas hidráulicas, que foram escolhidas como "família de produtos", neste estudo de caso.

Figura 3 - Luvas de bombas hidráulicas

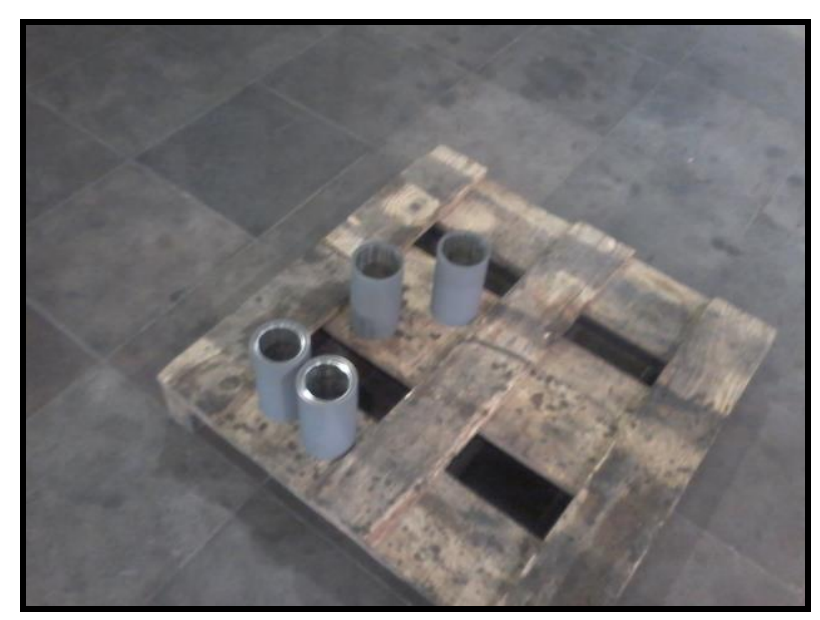

Fonte: Elaborado pelos autores 
As peças analisadas passam por quatro processos do sistema produtivo da empresa:

Inspeção: Tem a função de garantir que o produto veio de acordo com as especificações do cliente e a identificação de possíveis defeitos que possam dificultar os processos seguintes. O processo é realizado pelo responsável técnico da produção.

Preparação (Jateamento): Consiste em retirar com água através de uma máquina, resíduos da superfície da peça para que a mesma possa receber o revestimento metálico. O processo demanda um operário.

Aspersão Térmica (Metalização): É a operação mais importante para o cliente. Consiste na deposição do pó de cromo na superfície da peça. As Figuras 4 e 5 apresentam, respectivamente, uma explicação técnica do processo de aspersão térmica e o registro da máquina operando durante o processo.

Polimento: Consiste em ajustar a espessura do revestimento de acordo com a especificação imposta pelo cliente. Este processo demanda um operário e uma máquina. Como o operador já verifica as especificações do produto durante o processo, não necessita ser feita uma nova inspeção antes da expedição do produto para o cliente.

Figura 4 - Processo de Apersão Térmica

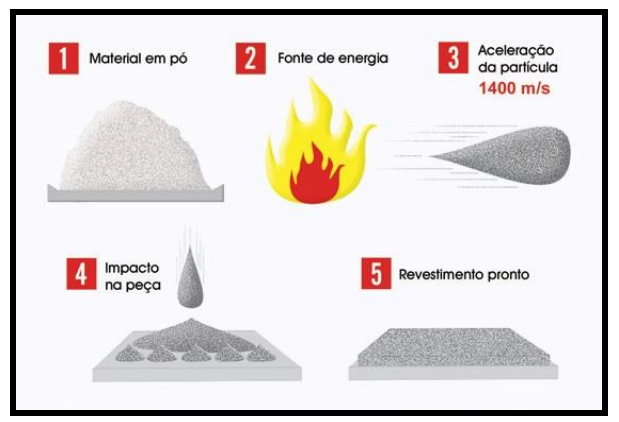

Fonte: site da empresa

Figura 5: Máquina de aspersão térmica

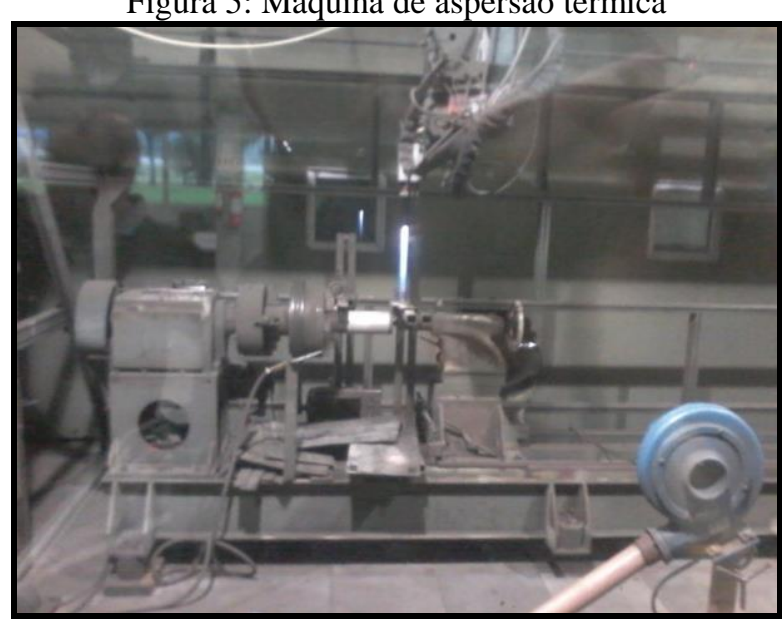

Fonte: Elaborado pelos autores 


\subsection{Desenho do estado atual do fluxo de valor}

Antes da elaboração do desenho do Mapa de Fluxo de Valor do estado atual foram coletadas as informações fundamentais sobre o produto analisado. Sabe-se que a empresa trabalha em dois turnos, das 07h00min ás 17h00min com um intervalo de 1 hora para o almoço, ou seja, são cerca de 31.200 segundos disponíveis para trabalhar, incluindo-se os tempos para manutenção e pausas. O cliente exige que o lote de 6 peças fique pronto em 2 dias. $\mathrm{O}$ cliente envia dois lotes por semana do produto.

O desenho do Mapa de Fluxo de Valor do estado atual, apresentado na Figura 6, foi realizado no software smart draw.

Figura 6 - Mapa do fluxo de valor do estado atual

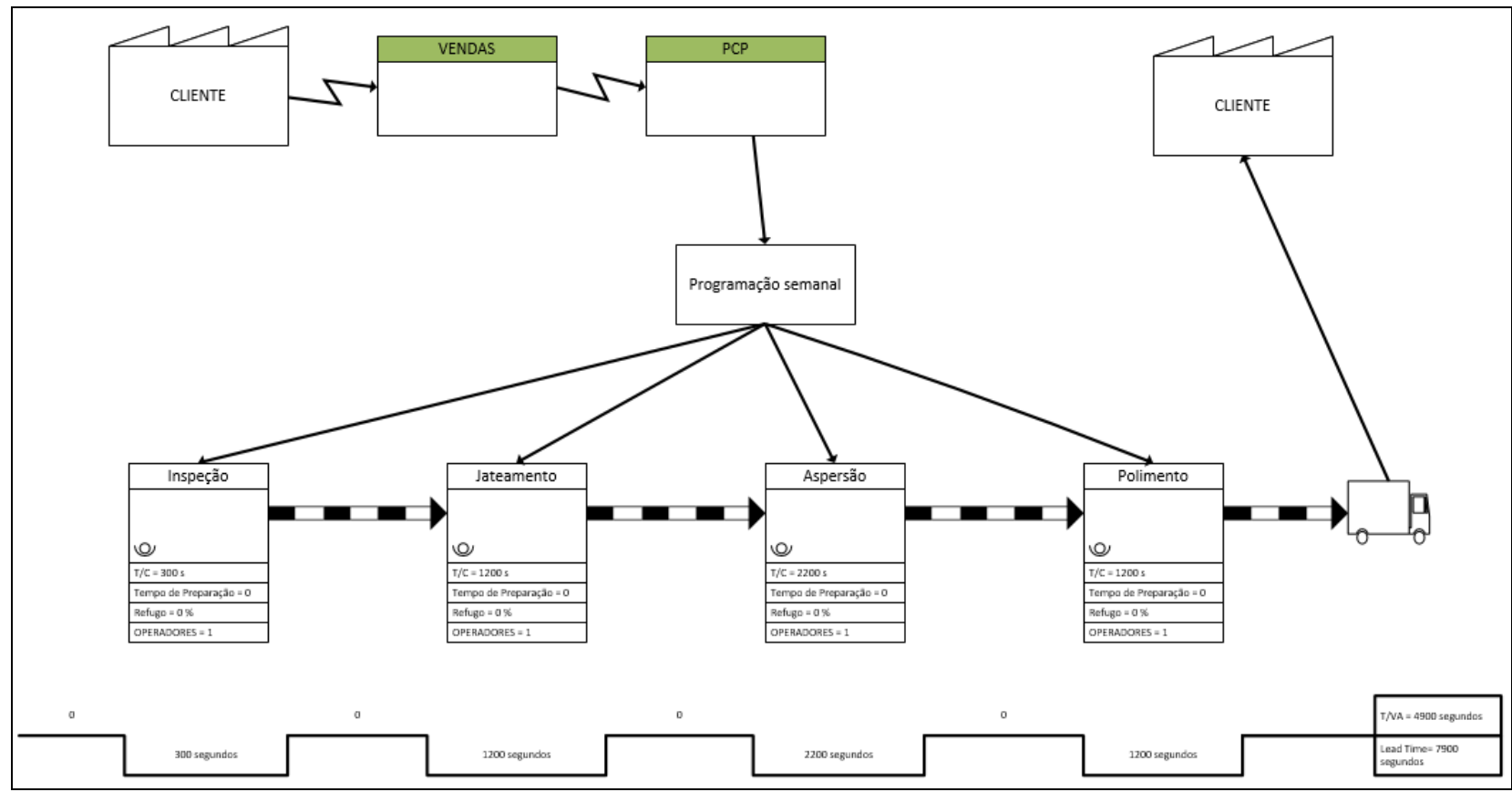

Fonte: Elaborado pelos autores

Percebe-se que o tempo de agregação de valor do produto em comparação com o tempo pelo qual ele passa por todos os processos tem uma diferença grande. Em contrapartida, não há formação de estoques intermediários, pois os lotes são pequenos e o nível de produção está baixo.

Durante as observações feitas em cada processo, ficou perceptível que o tempo de preparação da máquina poderia ser reduzido se houvesse um Kanban para o estoque de matéria prima, sobretudo no processo de aspersão. O operário do processo teve de realimentar a máquina com o pó de cromo, durante a operação e teve de buscar no almoxarifado mais matéria-prima, perdendo cerca de 300 segundos na operação.

\subsection{Desenho do estado futuro do fluxo de valor}


Para a elaboração do desenho do Mapa de Fluxo de Valor do estado futuro foram consideradas as informações realizadas no sistema produtivo, e analisou-se quais perdas poderiam ser eliminadas. Neste sentido, observou-se que a introdução de um Kanban para o abastecimento da matéria prima iria auxiliar o processo, eliminando possíveis desperdícios de tempo de abastecimento. O desenho do Mapa de Fluxo de Valor do estado futuro indica como ficaria o sistema produtivo com a introdução do Kanban sugerido, o que é mostrado na Figura 7.

Figura 7 - Mapa do fluxo de valor do estado futuro

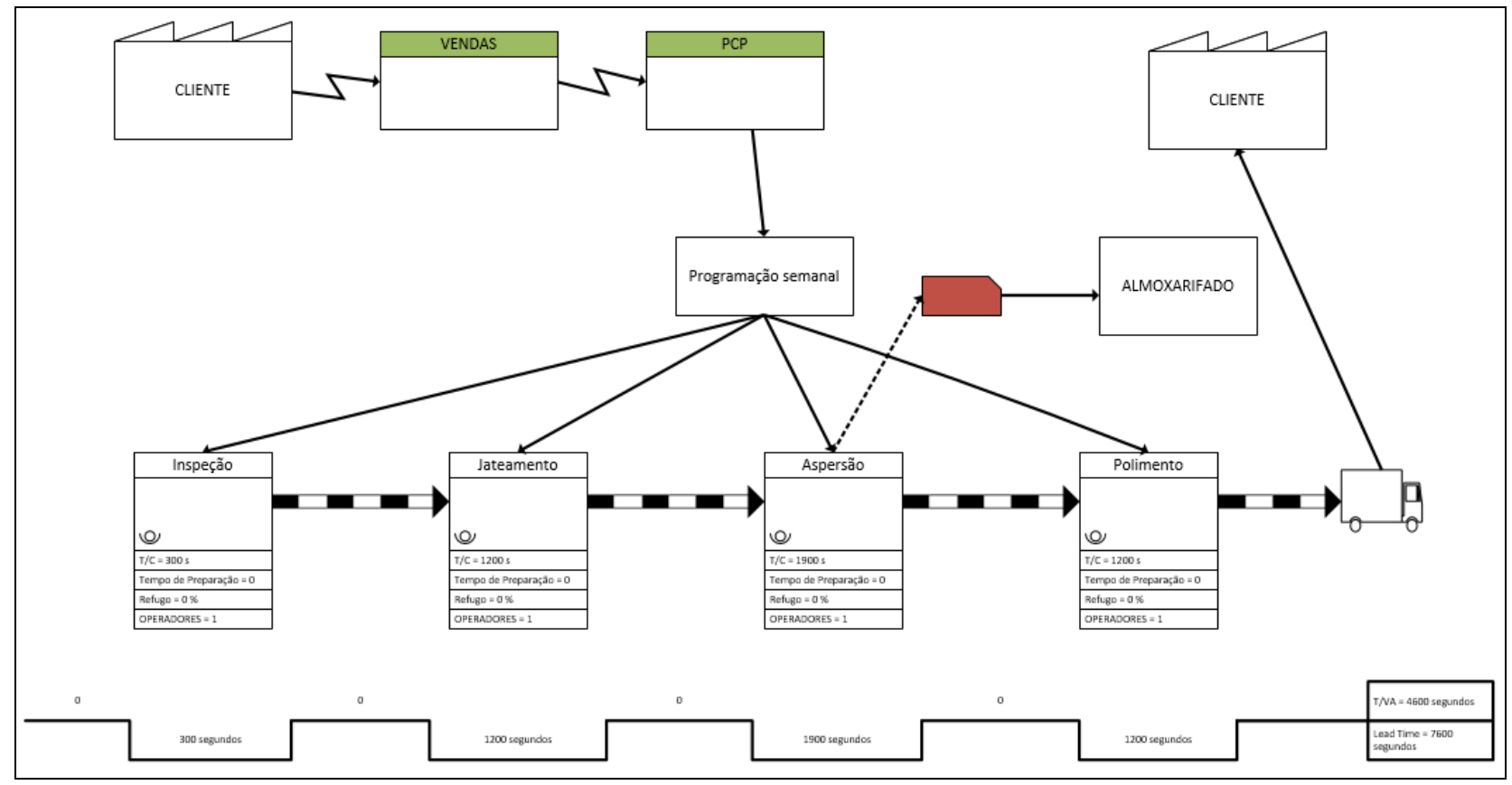

Fonte: Elaborado pelos autores

\subsection{Implementação de melhorias}

Para implantar a melhoria proposta pela introdução do Kanban, utilizou-se a ferramenta 5W2H como forma de estruturar um plano de ação. Este plano de ação, mostrado no Quadro 1, indica claramente as ações que devem ser realizadas a implantação do Kanban.

Quadro 1 - Plano de ação para implementar o Kanban de matéria prima

\begin{tabular}{|c|c|c|}
\hline \multicolumn{3}{|r|}{ Método 5W2H } \\
\hline \multirow{5}{*}{$5 w$} & O que? & Kanban de matéria prima \\
\hline & Quem? & $\begin{array}{l}\text { Operário da Aspersão, Responsável do Almoxarifado, gerente de produção e operador de } \\
\text { empilhadeiras. }\end{array}$ \\
\hline & Onde? & Máquina de aspersão e almoxarifado \\
\hline & Quando? & $\begin{array}{l}\text { No mês seguinte para que os funcionários recebam o devido treinamento ( } 4 \text { horas) para } \\
\text { utilizar a ferramenta. }\end{array}$ \\
\hline & Por quê? & Evitar perdas por falta de matéria-prima \\
\hline $2 \mathrm{~h}$ & Como? & $\begin{array}{l}\text { O gerente de produção irá montar os Kanbans de matéria prima e disponibilizará no } \\
\text { almoxarifado e na máquina de aspersão. Os funcionários deverão atualizar e checar as } \\
\text { informações do Kanban constantemente e seguir as indicações do mesmo.O funcionário do } \\
\text { almoxaifado deve repor sempre que necessárioa matéria prima próximo ao depósito da } \\
\text { máquina. }\end{array}$ \\
\hline
\end{tabular}


Fonte: Elaborado pelos autores

O Kanban de matéria prima será gerenciado pelo operador da máquina de aspersão térmica, conforme informações descritas no Quadro 2.

Quadro 2 - Kanban de matéria prima (processo de aspersão térmica)

\begin{tabular}{|c|c|c|c|c|c|}
\hline $\begin{array}{c}\text { Código do } \\
\text { produto }\end{array}$ & Descrição & $\begin{array}{c}\text { Peso da } \\
\text { embalagem }\end{array}$ & Consumido até agora & $\begin{array}{c}\text { Ponto de } \\
\text { pedido }\end{array}$ & $\begin{array}{c}\text { Ponto de } \\
\text { alarme }\end{array}$ \\
\hline 12000 & Pó de Cromo & $7 \mathrm{~kg}$ & atualizado pelo operador & $4 \mathrm{~kg}$ & $5 \mathrm{~kg}$ \\
\hline 12001 & Pó de Níquel & $7 \mathrm{~kg}$ & atualizado pelo operador & $5 \mathrm{~kg}$ & $6 \mathrm{~kg}$ \\
\hline 12002 & Pó de Tungstênio & $10 \mathrm{~kg}$ & atualizado pelo operador & $7 \mathrm{~kg}$ & $9 \mathrm{~kg}$ \\
\hline 12003 & Pó cerâmico & $5 \mathrm{~kg}$ & atualizado pelo operador & $3 \mathrm{~kg}$ & $4 \mathrm{~kg}$ \\
\hline
\end{tabular}

Fonte: Elaborado pelos autores

O Kanban de matéria prima possui cartões de atualização dos níveis de consumo da matéria prima, conforme mostrado no Quadro 2, e cartões verdes e vermelhos (um para cada produto).

O operador deve atualizar a lápis constantemente a coluna Consumido até agora nos cartões impressos, conforme o Quadro 2 e, assim que o peso consumido atingir o Ponto de pedido ele deverá colocar o cartão no envelope verde e posicionar o envelope verde no dia correspondente do calendário Kanban. Caso o responsável do almoxarifado não reponha a matéria prima e o consumo venha a atingir o ponto alarme, o operador deverá colocar o cartão no envelope vermelho.

O Quadro 3 apresenta o calendário Kanban. As colunas em verde representam os envelopes que indicam o Ponto de pedido, que indicam que a matéria prima está acabando e pode ser reposta. As colunas em vermelho representam os envelopes que indicam o Ponto de alarme que indicam que a matéria prima pode acabar a qualquer momento e o risco de perda por falta da mesma é grande.

O funcionário do almoxarifado deve conferir o quadro Kanban constantemente e, consequentemente repor a matéria prima, de preferência quando o envelope estiver verde, no depósito próximo à máquina de aspersão. O quadro Kanban deve ficar localizado em um ponto visível para que todos os que passam pela máquina possam visualiza-lo.

Quadro 3 - Calendário Kanban

\begin{tabular}{|c|l|l|l|l|}
\cline { 2 - 5 } \multicolumn{1}{c|}{} & Pó de Cromo & Pó de Níquel & Pó de Tungstênio & Pó cerâmico \\
\hline Segunda-feira & & & & \\
\hline Terça-Feira & & & & \\
\hline Quarta-feira & & & & \\
\hline Quinta-feira & & & & \\
\hline Sexta-feira & & & & \\
\hline
\end{tabular}


Fonte: Elaborado pelos autores

\section{Considerações Finais}

Neste artigo inicialmente destacamos a importância dos conceitos do Lean Thinking que parte do pressuposto que cinco princípios devam ser considerados, são eles: valor, fluxo de valor, fluxo contínuo, produção puxada e perfeição. Apresentamos de um referencial teórico sobre o LM, enfatizando principalmente os conceitos relacionados com o MFV. Abordamos a ferramenta $5 \mathrm{~W} 2 \mathrm{H}$ que também surgiu no contexto do LM como auxilio na tomada de decisões de um plano de ação. Ressaltamos que entender o fluxo do valor nos permite identificar e redefinir processos, de forma a reduzir, ou até, eliminar o que não é percebido como agregação de valor.

O trabalho deste artigo inseriu-se na área de Gestão de Sistemas de Produção e Operações, com a realização de um estudo de caso em uma empresa que aplica revestimentos contra desgastes em peças industriais. O estudo de caso teve como objetivo principal investigar o fluxo de valor de um processo produtivo da empresa. Foram aplicados conceitos referentes ao MFV e ao LM de acordo com a metodologia proposta em Rother e Shook (2012), identificando-se perdas e propondo melhorias.

Para alcançar o objetivo do estudo de caso foram analisados os processos fabris da empresa estudada para então identificar a família de produtos a ser analisada; compreender o fluxo de materiais e de informações existentes; identificar os desperdícios e assim elaborar uma proposta para o estado futuro desejado. Além disso foi elaborado um plano de ação para implantar as melhorias propostas. A coleta e análise de dados nos permitiu que o MFV assim como o 5W2H fossem usados de forma concreta na solução de problemas e na tomada de decisões gerenciais.

Este trabalho permitiu uma compreensão mais clara do Fluxo de Valor do sistema produtivo da empresa analisada, mostrando como é possível enxergar os problemas de fluxo de valor, assim como estruturar um plano de ação para implementar as melhorias observadas. O mapa do fluxo de valor do estado atual possibilitou a percepção de perdas no tempo de agregação de valor ao produto. $\mathrm{O}$ plano de ação $5 \mathrm{~W} 2 \mathrm{H}$ permitiu uma visão objetiva da implantação de melhorias. O trabalho apresentou uma metodologia estruturada para que a empresa compreendesse como pode analisar e implementar melhorias.

\footnotetext{
Abstract

Lean production proposes to simplify the production process by eliminating waste. Therefore, it is necessary to visualize the production process, in order to understanding how materials and processes flow through your production to identify the waste. The Value Stream Mapping (VSM) has been an important tool of lean production system used for the identification and elimination of waste. MFV in the manufacture of the product is represented by its production processes arranged in sequence to obtain visible in the production process in order to simplify it. This paper presents a
} 
theoretical review, which describes some concepts and definitions of lean production, the VSM as well as the tools used. The article presents a case study in a metallurgic industry. In the case study the flow of the material and the information was mapped in order to identify the waste and the source thereof in the amount of flow. After identifying the bottlenecks, it was drawn up the map of the "future state" showing up as the value should flow, and creating a plan of action to give effect to the proposals for improvements.

Key-words: value stream mapping; lean production; metallurgical industry.

\section{Referências}

CORRÊA, H.L.; GIANESI, I.G.N.; CAON, M. Planejamento, Programação e Controle da Produção. São Paulo: Atlas, 1996.

FERRO, J.R. Site do Lean Institute Brasil (coluna de José Roberto Ferro). A essência da ferramenta "Mapeamento do Fluxo de Valor". São Paulo: Lean Institute Brasil Disponível em: www.lean.org.br. Acesso em: julho de 2015.

NAZARENO, R.R. Desenvolvimento e aplicação de um método para aplicação de sistemas de produção enxuta. Dissertação (Mestrado), Escola de Engenharia de São Carlos, Universidade de São Paulo. São Carlos, 2003.

POLACINSKI, E.; VEIGA, R.S.; SILVA, V.B.; TAUCHEN, J.; PIRES; M.R.. Implantação dos 5Ss e proposição de um SGQ para uma indústria de erva-mate. Congresso Internacional de Administração, 2012. Disponível em: http://www.admpg.com.br/2012/down.php?id=3037\%20\&q=1. Acesso em: julho de 2015.

ROTHER, M.; HARRIS, R. Criando fluxo continuo - um guia de ação para gerentes engenheiros e associados da produção. São Paulo: Lean Institute Brasil, 2002.

ROTHER, M.; SHOOK, J. Aprendendo a enxergar: mapeando o fluxo de valor para agregar valor e eliminar o desperdício. São Paulo : Lean Institute Brasil, 2012.

SALGADO, G.E.; MELO,C.H.P.; SILVA,C.E.S.; OLIVEIRA, E.S. ;ALMEIDA, D.A. Análise da aplicação do Mapeamento do Fluxo de Valor na identificação de desperdícios do processo de desenvolvimento de produtos. Gestão \& produção, São Carlos, v. 16, no 3,p. 344-346. 2009.

SHINGO, S. O Sistema Toyota de Produção do Ponto de Vista da Engenharia de Produção. Porto Alegre: Bookman. 1996.

WOMACK, J.P.; JONES, D.T. A mentalidade enxuta nas empresas: elimina desperdícios e cria riqueza. Rio de Janeiro: Elsevier, 2004.

\section{Dados dos autores:}

Nome completo: Rogério Royer

Filiação institucional: Universidade Federal de Pelotas, Pelotas (RS)

Departamento: Centro de Engenharias - Engenharia de Produção

Função ou cargo ocupado: Professor do Magistério Superior

Endereço completo para correspondência: Centro de Engenharias-Prédio da Antiga Cotada, Rua

Benjamin Constant, 989 - Porto Pelotas - RS, Brasil - CEP 96010-020

Telefones para contato: +55 (53) 3284-1700

E-mail: rogroyer@ufrgs.br 
Nome completo: Ariane Ferreira Porto Rosa

Filiação institucional: Universidade Federal de Pelotas, Pelotas (RS)

Departamento: Centro de Engenharias - Engenharia de Produção

Função ou cargo ocupado: Professor do Magistério Superior

Endereço completo para correspondência: Centro de Engenharias-Prédio da Antiga Cotada, Rua

Benjamin Constant, 989 - Porto Pelotas - RS, Brasil - CEP 96010-020

Telefones para contato: +55 (53) 3284-1700

Email:afprosa61@gmail.com

Nome completo: Lucas Nienow dos Santos

Filiação institucional: Universidade Federal de Pelotas, Pelotas (RS)

Departamento: Centro de Engenharias - Engenharia de Produção

Função ou cargo ocupado: Acadêmico de Bacharelado em Engenharia de Produção

Endereço completo para correspondência: Centro de Engenharias-Prédio da Antiga Cotada, Rua

Benjamin Constant, 989 - Porto Pelotas - RS, Brasil - CEP 96010-020

Telefones para contato: +55 (53) 3284-1700

E-mail:lgns.santos@gmail.com

Submetido em: 23-06-2016

Aceito em: 21-09-2016 